\title{
GEOPOLÍTICA E CONSTITUIÇÃO À LUZ DO ESTADO DEMOCRÁTICO DE DIREITO
}

\author{
Guilherme Sandoval Góes ${ }^{1}$
}

\section{Introdução}

O presente artigo é fruto de pesquisa desenvolvida no estágio pósdoutoral do Programa de Pós-Graduação em Ciências Aeronáuticas da Universidade da Força Aérea (PPGCA), cujo tema era "Geopolítica, Cultura e Direito: Diálogos epistemológicos necessários em tempos de estatalidade pósmoderna”. Assim sendo, colima examinar as conexões científicas que unem a geopolítica e o direito, disciplinas que se imbricam de tal maneira que acabam desaguando na garantia de direitos fundamentais para o cidadão comum.

Com efeito, para realizar sua função de distribuir justiça e garantir direitos fundamentais, a Constituição de I988 não pode ficar ao largo da geopolítica, da mesma forma que a geopolítica, na sua tarefa de promover o desenvolvimento nacional, não pode fica alheia ao texto constitucional, devendo seguir fielmente as normas do Estado Democrático de Direito e da Ordem Jurídica Internacional das Nações Civilizadas. Infelizmente, há que reconhecer que esta linhagem epistemológica ainda é incipiente no Brasil. No entanto, não se pode negar que, em tempos de globalização da economia, é dever do estrategista brasileiro ganhar visão prospectiva de longo prazo para saber "jogar o jogo estratégico do geopoder mundial" dentro dos limites impostos pela Constituição e pelo Direito Internacional Público, da mesma forma, que é dever do jurista pátrio saber "interpretar estrategicamente a Constituição à luz dos impactos advindos das disputas geopolíticas do cenário internacional".

Isto significa dizer que a busca do desenvolvimento geopolítico do País não deve se afastar dos pilares democráticos da Constituição Cidadã de I988, daí a relevância do geodireito, aqui vislumbrado como ramo autônomo da ciência, que se destina a examinar as interconexões entre o direito e a geopolítica. Sob a ótica do geodireito, a estratégia ganha maior visão jurídica

I Professor Emérito da Escola de Comando e Estado-Maior do Exército (ECEME). 
e o direito ganha maior visão estratégica, uma vez que a ordem geopolítica mundial e o direito constitucional são colocados lado a lado, com o objetivo de examiná-los sistematicamente como um todo epistemológico ${ }^{2}$.

Em consequência, tudo parece indicar que o geodireito é o prenúncio de um novo tempo científico, no qual estadistas, estrategistas, juízes, legisladores democráticos, constitucionalistas, internacionalistas e operadores do direito em geral, terão que repensar as conexões envolvendo a normatividade do direito e a ação estratégica do Estado. É dentro deste quadro de complexidade multidisciplinar que o geodireito se apresenta como última fronteira científica, seja da geopolítica, seja do direito, ou seja, tanto existe um controle geopolítico do direito (constitucionalização da geopolítica), quanto um controle jurídico da geopolítica (judicialização da geopolítica).

Infelizmente, o tema do geodireito é praticamente inédito no Brasil. Não temos nenhuma grande obra acadêmica sobre este assunto, como na Itália, por exemplo. Lá, existem diversos estudiosos, dentre eles o eminente e notável jurista Natalino Irti (2005) com a obra "Norma e lugar: princípios de geodireito", cuja linha científica dominante estuda as relações entre as forças desregulamentadoras da economia e da tecnologia e o direito na periferia do sistema mundial (Irti 2005).

Da mesma forma, Philip Bobbitt (2003), nos Estados Unidos, desenvolve densa literatura sobre as relações epistêmicas entre a estratégia nacional, o direito constitucional e o direito internacional público. Aliás, são as próprias palavras de Bobbitt que mostram essa sua característica dual de constitucionalista e estrategista:

Talvez esta convicção deva-se à minha história pessoal incomum: às vezes acho não só que estava fadado a escrever este livro, como talvez que eu seja um dos poucos que desejariam fazê-lo. Afinal, nos últimos 25 anos, levei uma vida dupla. Como professor, dividi minha vida entre o Texas e a Inglaterra. Nos Estados Unidos, ensino direito constitucional na

\footnotetext{
2 Com esse tipo de intelecção em mente, é possível compreender a influência da geopolítica mundial, que, praticamente, impõe determinadas alterações nas Constituições dos países em desenvolvimento. Em essência, o geodireito coloca as variáveis geopolíticas em contato direto com as variáveis jurídicas, dentro de uma simbiose multidisciplinar que faz avançar o direito e a própria geopolítica. Pode-se definir geodireito como o ramo do conhecimento científico que se destina a examinar as relações epistemológicas entre a geopolítica e o direito (sentido amplo), bem como as relações epistemológicas entre a interpretação constitucional e a grande estratégia nacional (sentido estrito). Nesse sentido, o geodireito é a base científica do estadista na sua tarefa de promover o desenvolvimento nacional, da mesma forma que é a base científica do juiz na sua tarefa de decidir sobre uma questão geopolítica fundamental do Estado brasileiro (Góes e Visentini 2019, 28-29).
} 
Universidade do Texas; no Reino Unido, dei aulas de estratégia nuclear, primeiro em Oxford e mais tarde no Kings College em Londres. (Bobbitt 2003, 3 dos agradecimentos).

Em suma, a intenção aqui foi mostrar o vasto caminho a percorrer, seja pela geopolítica, seja pelo direito constitucional, no sentido de delinear os elementos teóricos do encontro científico entre a Grande Estratégia de Desenvolvimento Nacional e a Constituição Cidadã de I988, mormente nesses tempos sombrios de globalização pós-pandemia mundial. É nesse diapasão que desponta a relevância do estudo da judicialização da geopolítica, fenômeno no qual as grandes decisões geopolíticas do Estado brasileiro serão levadas para julgamento do Poder Judiciário, notadamente, do Supremo Tribunal Federal (STF). É por isso que o presente trabalho sustenta a tese de que a razão pela qual juízes e tribunais devem conhecer a geopolítica mundial é muito simples, qual seja: eles vão decidir o futuro geopolítico do País a partir da judicialização de questões geopolíticas fragmentadas do jogo de poder mundial.

Em consequência, o objetivo central desse artigo é investigar, inicialmente, os caminhos trilhados pela globalização neoliberal, desde o fim da Guerra Fria, em I989, perpassando pelo ataque terrorista de iI de setembro de 200 I e pela crise financeira de 2008 , até alcançar a pandemia mundial do vírus Covid-ı9 (I989-20I9). Para tanto, além dos arquétipos estratégicos norte-americanos que serão examinados (National Security Strategy ou NSS de Clinton, Bush, Obama e Trump), é imperioso ainda analisar a influência do poder hegemônico das potências industrializadas sobre os países de modernidade tardia do Sul Global, como, lamentavelmente, é o caso do Brasili3.

$\mathrm{Na}$ sequência, sob os influxos desta verticalização de relações geopolíticas hierarquizadas, pretende-se formular as bases teóricas de uma geopolítica autóctone, genuinamente atrelada à identidade nacional e com latitude cratológica suficiente para garantir a expansão do núcleo estratégico

3 Com efeito, o fim da Guerra Fria, em I989, trouxe efeitos nocivos em relação às nações da África, das Américas Central e Latina e da maior parte da Ásia, que são coletivamente conhecidas como o Sul Global. Infelizmente, a situação desses países subdesenvolvidos do Sul Global projeta um quadro paradoxal que pode tanto gerar desenvolvimento econômico e social quanto agravar ainda mais a pobreza, a degradação ambiental, a fome e a violação dos direitos humanos do Sul Global, ao contrário do Centro Global, formado pelos países ricos que controlam o processo de tomada de decisões do sistema internacional. (...) Nos últimos tempos, a discussão em torno dessas relações se há intensificado, especialmente a partir da tentativa de reconfiguração neoliberal do Estado, cuja proposta metodológico-científica restaura o modelo de estatalidade mínima com o objetivo de desregulamentar relações jurídicas privadas, relativizando o conceito de soberania (Góes 2019, 57-58). 
brasileiro, aqui definido como sendo o conjunto de segmentos econômicotecnológicos autônomos capazes de participar eficazmente da competição internacional. Nesse sentido, a pergunta é simples: um país com mais de 200 milhões de habitantes pode abrir mão do seu núcleo estratégico tecnológicoindustrial, transformando-se em mera sociedade de serviços, exportadora de produtos primários, sem valor agregado?

Eis aqui o grande dilema geopolítico dos países de modernidade tardia, como é o caso do Brasil: se se alinharem automaticamente às potências mundiais, provavelmente serão obrigados a aceitar o simples papel de exportadores de commodities. Por outro lado, se rejeitarem grandes acordos multilaterais de abertura comercial, poderão ficar isolados dos maiores mercados consumidores do planeta.

Portanto, conceber uma grande estratégia de desenvolvimento nacional a partir da manutenção e expansão do seu núcleo estratégico, parece ser o grande desafio da sociedade brasileira, aí incluídos juristas e estrategistas. É por tudo isso que o presente artigo tem o grande objetivo de identificar o papel geopolítico do Brasil dentro da reconfiguração da ordem mundial pósmoderna, que ainda se encontra em construção, mas que já coloca, de um lado, a era da desglobalização da economia mundial, patrocinada pela Doutrina Trump a partir da retomada do antigo conceito estratégico do America First da era eurocêntrica e, do outro, a potencialização da ordem mundial neoliberal, agora capitaneada pela geopolítica da China, restando indagar se o paradigma mackinderiano-spykmaniano da geopolítica clássica está sendo reescrito com tintas de pós-modernidade?

Com efeito, tudo indica que a reconfiguração da geopolítica póspandemia mundial será caracterizada não apenas pela ressignificação do papel social do Estado contemporâneo (Estado Liberal ou Estado Social), mas, também, pelo jogo de poder global entre os Estados Unidos da América (EUA) e a China. Enfim. Este é o espectro temático do presente artigo.

\section{Um Mundo a Ser Refeito: Entre a Desglobalização Americana e o Globalismo Neoliberal Chinês}

O objetivo dessa segmentação temática é apresentar a incrível velocidade de evolução da estatalidade pós-moderna que, em apenas três décadas, já produziu quatro grandes momentos de ruptura paradigmática da História da Humanidade, a saber: a queda do muro de Berlim (I989), a queda das Torres Gêmeas (200I), a crise financeira mundial (2008) e a crise sanitária da Covid-ıg (20I9). É nesse sentido que se afirma que a estatalidade 
pós-moderna, no auge dos seus trinta anos, vive as experiências protecionistas da era da desglobalização da economia, patrocinada pela Doutrina Trump, em decorrência da ascensão geopolítica da China e, na sua esteira, do declínio do mundo americano, aqui interpretado como a ordem neoliberal controlada pelos Estados Unidos, com o apoio dos seus aliados da tríade capitalista (Europa e Japão) ${ }^{4}$.

Trata-se do "giro geopolítico da desglobalização" criado pela América de Trump, que se afasta da liderança mundial da globalização neoliberal, para se aproximar da racionalidade econômica nacionalista, verdadeiramente protecionista, que viabiliza, por sua vez, a repatriação da indústria nacional como forma de estancar o engrandecimento do geopoder chinês em escala planetária. É importante, portanto, examinar se a geopolítica pós-Covid-I9 resgatará o mundo americano, caracterizado pelo controle hegemônico unilateral da globalização neoliberal, de inspiração lockeana ou, se, finalmente, despontará o mundo pós-americano, um sistema de governança global cosmopolita, de inspiração kantiana, compartilhado agora também com outras potências mundiais, notadamente a China da Iniciativa do Cinturão e da Rota da Seda.

No entanto, para entender plenamente tal contexto pós-pandemia mundial, é preciso retroceder aos tempos das Conferências de Bretton Woods, nos estertores da Segunda Grande Guerra Mundial, em julho de I944, para identificar três grandes eventos, que marcam o início do ciclo de hegemonia mundial dos Estados Unidos. Com efeito, a trajetória da América hegemônica começa com o sistema de gerenciamento financeiro internacional de Bretton Woods com a criação do Fundo Monetário Internacional (FMI), do Banco

4 Por óbvio que não se desconhece a ampla controvérsia que existe em torno da ideia de estatalidade pós-moderna, na qual diferentes constructos teóricos disputam a primazia acerca dessa matéria, daí toda uma plêiade de elementos fractais dispostos a representá-la, tais como: a descrença do discurso das metanarrativas da modernidade (Lyotard 2004), a lógica cultural do capitalismo tardio (Jameson 2002), a construção teórica da hipermodernidade (Lipovetsky 2004) e a linhagem epistêmica do medo líquido (Bauman 2008). Sem embargo dessa relevante controvérsia doutrinária há que se reconhecer, por outro lado, que o mundo pós-I989 apresenta grandes transformações na estrutura do poder mundial até então existente. É por isso que aqui se defende a visão de que a ordem mundial pós-moderna deve ser analisada menos como um fetiche acadêmico e mais como uma nova realidade geopolítica vinculante, que nasce do colapso da União Soviética como superpotência mundial, criando dessarte um novo arquétipo de relações de poder hegemônico, muito distinto de seus antecessores, quais sejam a ordem eurocêntrica (I648-I945) e a ordem bipolar (I945-I989). Assim, por refugir ao escopo desse artigo, tal controvérsia será aqui abandonada, optando-se pelo desenvolvimento de análise mínima que permita descrever essa possível ordem mundial pós-moderna, aqui vislumbrada como a ordem mundial que surge com o fim da Guerra Fria e que ainda se encontra em construção até os dias de hoje. 
Mundial (BIRD) e do sistema dólar-ouro, três grandes acontecimentos, que demarcam a aliança dos países industrializados vencedores da Segunda Guerra Mundial sob a liderança estadunidense.

Ato contínuo, o gênio pragmático do estrategista norte-americano logo percebeu que era necessário também promover a reconstrução democrática dos seus ex-inimigos, Alemanha e Japão, como forma de afastar a ameaça comunista, daí a formulação do Plano Marshall de I947. Eis, aqui, portanto, o embrião da tríade capitalista dos dias de hoje (bloco americano controlado pelos EUA, bloco europeu liderado pela Alemanha e bloco asiático regido pelo Japão). Ou seja, um arquétipo de relações internacionais que converge geopoder para um pequeno número de potências industriais, sob os influxos de um Estado dominante, que se sente capaz de liderar o sistema internacional.

$\mathrm{Na}$ sequência da linha do tempo, continua o caminho do ciclo hegemônico dos EUA, agora com a inauguração do Clube de Paris de Estados rentistas, em I956, que surge como instrumento de controle da economia mundial periférica por parte dos países credores (mais uma vez, percebe-se aqui a concentração de poder no clube dos ricos da América do Norte, Europa Ocidental e Japão). Na mesma toada, segue a trilha da América hegemônica com criação do Clube de Roma, em I968, cujo objetivo era construir cenários prospectivos para a formulação de políticas globais 5 .

Sem embargo da relevância de todos esses mecanismos multilaterais, o fato é que a ideia de pax americana vai ganhar visibilidade irrefutável a partir da declaração unilateral de I97I, de Richard Nixon, que reformulou o sistema de Bretton Woods, desatrelando o dólar americano do seu lastro em ouro, porém mantendo-o como referência mundial, agora, sem nenhum tipo de lastro, fato que evidentemente renovou - por combalida que estava com a Guerra do Vietnã - a hegemonia mundial americana, projetando-a vigorosamente para o futuro. Aliás, observe, com atenção, que a declaração unilateral de I97I (Nixon Shock) é a base fundante da hegemonia monetáriofinanceira americana e da própria pax americana até os dias de hoje.

Portanto, advoga-se aqui a tese de que o fim do dólar como referência do sistema monetário-financeiro global indicará o fim do mundo americano. É nesse sentido que vislumbro a guerra do século XXI como sendo a guerra financeira do dólar americano contra renminbi chinês. Retomando a longa

\footnotetext{
5 Formada por personalidades ilustres (dentre outros, estadistas, economistas, industriais, líderes políticos, pedagogos e humanistas), o Clube de Roma, após seu famoso relatório Dana Meadows de 1972, foi muito criticado pela sua tendência de não representar a humanidade, afastando-se, na visão de Philippe Braillard, da sua oposição de defensor da sobrevivência da espécie humana, para se aproximar de uma ideologia tecnocrática, dentro de sociedade mundial guiada pela gestão de empresas multinacionais (Mafra 2006, I74).
} 
sequência de eventos que consolidam a hegemonia americana, impende agora destacar a criação, em I975, do Grupo dos Sete Países mais ricos e industrializados do mundo $\left(\mathbf{G}_{7}\right)$.

Com a devida agudeza de espírito, o leitor deve perceber que o G7 deu sistematicidade intrínseca à pax americana, na medida em que estabeleceu um arquétipo de geopoder com o objetivo de controlar o mundo a partir de políticas mundiais uníssonas focadas nos fluxos comerciais e de investimentos em escala planetária, fortalecendo, assim, a tríade do capitalismo democrático (EUA, Europa e Japão). Com tal tipo de intelecção em mente, fica mais fácil compreender que o G7 tem sua origem mais remota nos Clubes de Paris e de Roma e, mais próxima, na comissão trilateral de I973, materializada por David Rockefeller e Brzezinski, cuja finalidade era desenvolver a cooperação entre as regiões mais desenvolvidas do planeta, Europa Ocidental, Japão e América do Norte. Destacando a importância da comissão trilateral, ensina o saudoso mestre e amigo Roberto Machado de Oliveira Mafra:

A (Comissão) Trilateral era, segundo alguns, o "braço financeiro" da Nova Ordem Mundial que seria implantada no mundo, para serem evitados os cenários negativos oriundos dos relatórios do Clube de Roma, sendo que esse "novo ordenarnento" seria materializado sob a forma de um Governo Único Transnacional Mundial. Foram apresentados três blocos (Tríade), previstos inicialmente como base - os Estados Unidos da América, a Europa e o Japão - de onde eram originários seus principais integrantes, representando a elite mais influente de vários países - banqueiros, industriais, empresários, cientistas, economistas, militares, políticos e outros - e que comporia o núcleo da Comissão Trilateral. [...] O grande objetivo da Trilateral era unir, economicamente, o mundo inteiro, para o que os três grandes blocos citados ficariam sob a "área de influência" dos Estados Unidos da América, materializando uma Nova Era "profetizada" por Brzezinski como a (Era da Eletrônica) (Mafra 2006, I76-I77).

De tudo se vê, portanto, o longo caminho percorrido pela América hegemônica, desde Bretton Woods (I944), perpassando pelo Plano Marshall (I947), Clubes de Paris (I956) e Roma (I968), declaração unilateral de desvinculação do dólar ao ouro (I97I), Comissão Trilateral (I973), criação do G7 (I975) e desalinhamentos cambiais do Acordo de Plaza (I985) ${ }^{6}$, até, finalmente, chegar-se à queda do muro de Berlim, em I989, apogeu do ciclo hegemônico

6 O Acordo de Plaza, imposto pelos Estados Unidos, em setembro de 1985 , forçou a valorização do iene japonês e do marco alemão, com o objetivo de baixar a cotação do dólar norte-americano, propiciando assim aos EUA a redução do seu déficit comercial, bem como recuperando sua competitividade internacional em relação à Alemanha e ao Japão. 
da pax americana, impulsionado que foi pelo colapso da União Soviética. Com efeito, a queda do muro de Berlim inaugurou a globalização neoliberal, regida pela pax americana, na qual a única superpotência remanescente do planeta ficaria encarregada de patrocinar a abertura mundial da economia, ao mesmo tempo em que garantiria a paz mundial. Isto significa dizer que a pax americana passou a ser o motor da governança neoliberal pós-I989, fazendo valer a ideia de que o termo globalização pode e deve ser associado ao projeto hegemônico da pax americana.

E mais: com a devida agudeza de espírito, observe que a hegemonia mundial americana, de acordo com a Estratégia do Engajamento e da Ampliação de Clinton, seria exercida pelo grandioso esquema da Constelação Mundial do Comércio, composto de três grandes áreas supercontinentais de comércio, a saber: Área de Livre Comércio das Américas (ALCA); Mercado Transatlântico (TM) e Cooperação Econômica da Ásia-Pacífico (APEC). Tal arquétipo teria como elementos de apoio os tradicionais mecanismos de Bretton Woods (FMI, BIRD e dólar sem lastro em ouro), acrescido agora da Organização Mundial do Comércio (OMC), que surge, em I994, a partir da chamada Rodada Uruguai do Acordo Geral sobre Tarifas e Comércio (GATT).

Eis aqui, estampado com todas as letras, o estágio mais avançado da teoria da tríade capitalista, ou seja, o bloco americano agora é a Área de Livre Comércio das Américas, o bloco europeu é o Mercado Transatlântico e o bloco asiático é a Cooperação Econômica da Ásia-Pacífico. Enfim, reitera-se aqui a pax americana pela globalização neoliberal, bem como a globalização neoliberal pela Constelação Mundial do Comércio (estágio mais avançado da teoria da tríade).

É nesse contexto de globalização neoliberal que desponta a tese do fim da história de Francis Fukuyama (I998), deslocando para o epicentro da estatalidade pós-moderna o triunfo do capitalismo financeiro, a vitória da democracia liberal, a universalização dos valores ocidentais, o fim dos conflitos civilizacionais e a supremacia de uma só superpotência remanescente ${ }^{8}$.

7 É nesse sentido que Vicente de Paulo Barreto associa o termo "globalização" ao projeto hegemônico de poder da "pax americana": "O termo 'globalização' foi, também, associado a um projeto sociopolítico, a Pax Americana, que após a queda do Muro de Berlim, foi considerado como hegemônico. O projeto, tanto para alguns teóricos, como na prática das relações financeiras, passou a ser considerado como qualitativamente superior aos demais modelos de regimes políticos, econômicos e sociais, encontrados nas diferentes nações do planeta. [...] Ao lado dessa brusca mudança no cenário político global, pela primeira vez na história da humanidade um sistema econômico pretende-se universal, surgindo mecanismos de produção comuns a todos os povos" (Barretto 20I0, 215-2I6).

8 Como bem destaca Luís Roberto Barroso: "Planeta Terra. Início do século XXI. Ainda sem contato com outros mundos habitados. Entre a luz e sombra, descortina-se a pós-modernidade. 
Assim, sob o rótulo genérico da pax americana, projeta-se a "ontogenia do leviatã geopolítico”, na qual o poder superior dos Estados Unidos será o garantidor da paz e segurança do sistema internacional.

De fato, a América hegemônica sente-se na obrigação de orientar e comandar os destinos da humanidade, valendo destacar nesse sentido a visão de Zbigniew Brzezinski:

A América tem o monopólio do poder militar global, uma economia incomparável (segundo para ninguém) e uma inovação tecnológica inigualável, o que lhe confere uma influência política mundial única. Além disso, há um reconhecimento generalizado, ainda que não dito, de que o sistema internacional precisa de um estabilizador efetivo, e que a alternativa mais provável a curto prazo para o mundo americano é o caos (Brzezinsk 2007, 192) (grifos nossos).

Em consequência, o apotegma é simples: Ou o mundo aceita a hegemonia da pax americana ou viverá em permanente estado de desordem mundial (Góes 2018, 523-524) ${ }^{9}$. Enfim, a complexa dinâmica de domínio geopolítico do planeta perpassa, necessariamente, pela liderança mundial da globalização neoliberal. Toda a análise feita até aqui serviu para marcar bem o globalismo neoliberal regido pela América hegemônica, que, no entanto, começa a entrar em declínio com Doutrina Bush a partir de iI de setembro, com a queda das torres gêmeas.

Nesse sentido, Samuel Huntington não tardou a contestar a ideia fukuyamaniana de um só mundo de harmonia liberal, destacando que:

No mundo pós-Guerra Fria, pela primeira vez na História, a política mundial se tornou multipolar e multicivilizacional. No final da década de 80, o mundo comunista desmoronou e o sistema internacional da Guerra

O rótulo genérico abriga a mistura de estilos, a descrença no poder absoluto da razão, o desprestígio do Estado. A era da velocidade. A imagem acima do conteúdo. [...] Vive-se a angústia do que não pôde ser e a perplexidade de um tempo sem verdades seguras. Uma época aparentemente pós-tudo: pós-marxista, pós-kelseniana, pós-freudiana" (Barroso 2003, 2).

9 É nesse diapasão que se vive a era da desordem mundial, tão bem esgrimida pelo saudoso mestre Luiz Alberto Moniz Bandeira quando destaca que: "A Ciência Política necessita estudar a ontogênese do Estado, no processo da opressiva acumulação do poder capitalista, que não apenas se nega, [...], mas igualmente anula a negação, ao longo da história e da evolução da economia mundial [...] Há uma relação recíproca, de ação e reação, entre os acontecimentos, daí que temos de estudá-los em todas as suas dimensões ontológicas, sob novos e diversos ângulos, dado que a história evolui ad infinitum, não de forma retilínea, mas em espiral e, às vezes, em curvas, dobras e linhas alternadas" (Moniz Bandeira 20I6, 24-25). 
Fria virou história passada. No mundo pós-Guerra Fria, as distinções mais importantes entre os povos não são ideológicas, políticas ou econômicas. Elas são culturais. (...) A rivalidade das superpotências é substituída pelo choque de civilizações. A política mundial está sendo reconfigurada seguindo linhas culturais e civilizacionais (Huntington I998, I9-2I) (grifos dos autores).

De certa maneira, essa visão de Huntington não deixa de transitar na trilha científica da multipolaridade multicivilizacional, notadamente, a partir dos ataques terroristas no dia II de setembro de 200I ao World Trade Center e ao Pentágono, símbolos do poderio financeiro e militar estadunidense, cujo desfecho foi a implementação da Doutrina Bush do ataque preventivo, que denegou explicitamente a Ordem de Yalta. Com efeito, há que se reconhecer que os ataques aos símbolos do poder nacional norte-americano irão alterar drasticamente o quadro da globalização neoliberal até então vigente.

Nesse sentido, a configuração estratégica pós-II de setembro optou, sem maiores preocupações com o resto do mundo e nem com o direito internacional público, por um modelo de ataque preventivo, que inverteu o sinal com relação à NSS (National Security Strategy) de Clinton. Isto significa dizer que, enquanto a NSS de Clinton procurava manter a liderança global dos EUA a partir do controle da economia mundial, a NSS de Bush fez o contrário, potencializando a dimensão militar e, com isso, permitindo a paulatina projeção chinesa na África, na América Latina e parte da Ásia, com espeque no antiamericanismo. No dizer de Thomas Friedman, tem-se que:

Assim, as forças do "como globalizar" se dispersaram, e à medida que crescia o número de pessoas do Terceiro Mundo que se beneficiavam da globalização, e à medida que no governo Bush os Estados Unidos começaram a exercer maior poder militar unilateral, o elemento antiamericano no movimento antiglobalização passou a ter voz e papel muito mais importantes. Em consequência, o próprio movimento ficou ao mesmo tempo mais antiamericano e mais incapaz e menos disposto a desempenhar qualquer papel construtivo na formação do debate global sobre a forma da globalização (Friedman 2007, 348).

Sem embargo de tão relevante argumentação, o fato é que a decadência do mundo americano começou mesmo com a crise financeira neoliberal de 2008, que se intensificou ainda mais com a crise do coronavírus de 2019. Com efeito, a emergência sanitária em escala global projetou de certa maneira 
princípios de inspiração kantiana ${ }^{\mathrm{I}}$, que se contrapõem ao arquétipo neoliberal da globalização da tríade capitalista, que já se encontrava enfraquecida desde a deflagração de falência do Banco de Investimentos Lehman Brothers, em 2008.

É nesse sentido que se pode afirmar que a crise financeira de 2008 foi o eixo propulsor de uma verdadeira revolução copernicana no campo da geopolítica mundial, na medida em que trouxe com ela a real possibilidade de desconstrução do mundo americano e sua possível substituição por um mundo multipolar ou pelo menos por um mundo sem predominância cêntrica dos Estados Unidos e seus tradicionais mecanismos de hegemonia mundial (Góes 2018). Assim, após o período de quedas (I989-200I) ${ }^{\mathrm{II}}$, desponta o período de crises $^{\mathrm{I2}}$, que vai de 2008 (crise financeira do liberalismo) até os dias atuais (crise sanitária da Covid-I9); se o período de quedas (I989-200I) é de hegemonia americana incontrastável, o período de crises (2008-20I9) deve ser interpretado como um ciclo de mudança de poder global, caracterizado pela gradual transição para a multipolaridade welfarista em detrimento da pax americana neoliberal.

Todas as questões que foram até aqui levantadas podem e devem ser agrupadas sob o rótulo genérico de mundo pré-pandemia mundial, restando agora projetar o futuro de uma nova ordem mundial pós-coronavírus, cuja herança mais significativa deveria ser o reconhecimento da dignidade da pessoa humana como novo eixo axiológico do Estado Democrático de Direito, independentemente da alta tensão geopolítica entre gigantes do sistema internacional (EUA e China). Assim, tudo indica que a geopolítica pós-pandemia mundial deslocará para a centralidade da agenda das relações internacionais a disputa entre a retomada do globalismo neoliberal chinês (globalização-neoliberalismo) e a consolidação da desglobalização americana (repatriação da indústria nacional-isolacionismo).

Sem dúvida, a planetarização da epidemia da Covid-ıs já projeta a

Io Na visão de Giorgio Agamben, filósofo italiano, tem-se que: Essa indagação é ainda mais urgente, e não se trata apenas de uma hipótese puramente teórica, se é verdade, como se começa a dizer em diversos lugares, que a emergência sanitária atual pode ser considerada o laboratório no qual se preparam os novos arranjos políticos e sociais que aguardam a humanidade. Sei que não faltará quem responda que o mais grave sacrifício foi feito em nome de princípios morais. A esses gostaria de lembrar que Eichmann, aparentemente de boa-fé, não se cansava de repetir que tinha feito o que tinha feito de acordo com sua consciência, para obedecer àqueles que considerava os preceitos da moral kantiana. Uma norma que afirme que se deve renunciar ao bem para salvar o bem é tão falsa e contraditória quanto aquela que, para proteger a liberdade, impõe a renúncia à liberdade (Agamben 2020).

II Queda do muro de Berlim (I989) e queda das torres gêmeas (200I).

I2 Crise financeira neoliberal (2008) e crise do coronavírus (20I9). 
formação de uma nova ordem mundial, que se destacará não apenas pela ressignificação do papel do Estado hodierno no sentido de garantir direitos sociais do homem comum (garantia do núcleo essencial da dignidade humana para todos), mas, também, pelo jogo errático de poder global entre os Estados Unidos e a China, agora dentro de um novo arquétipo disruptivo pós-coronavírus, que reeditará o paradigma mackinderiano-spymaniano com tintas da estatalidade pós-moderna ${ }^{13}$. Com rigor, tal contexto já existia no mundo pré-Covid-I9, onde já se questionavam as vantagens e as desvantagens entre a Estratégia das Grandes Alianças Transoceânicas Neoliberais de Barack Obama e a Estratégia Neoisolacionista do América em Primeiro Lugar de Donald Trump.

Nesse sentido, analisando-se comparativamente a América de Obama e a América de Trump, constata-se que elas partiram de caminhos geopolíticos diametralmente opostos (globalismo neoliberal de Obama e desglobalização neoprotecionista de Trump), muito embora tivessem em mira o mesmo objetivo final: restaurar o mundo americano (pax americana), ameaçado diretamente pela ascensão geopolítica da China, notadamente a partir da convergência do Cinturão Econômico da Rota da Seda (por terra) e da Rota da Seda Marítima do Século XXI (por mar). De acordo com Estratégia de Obama, os Estados Unidos deveriam revitalizar sua liderança global, tendo como núcleo fundante do seu poderio global a retomada da teoria da tríade, esquecida que foi pela América de Bush, daí a visão de criar as grandes alianças transoceânicas com seus tradicionais parceiros capitalistas, quais sejam: a aliança transatlântica com a Europa e a aliança transpacífica com o Japão.

De outra banda, a novidade que a Doutrina Trump traz não é a colocação dos interesses americanos em primeiro lugar, mas, sim, a tentativa de conter o geopoder chinês em escala planetária pela adoção do nacionalismo econômico de repatriação da indústria nacional ${ }^{\mathrm{I} 4}$. Na visão de Trump, urge

I3 É nesse sentido que estadistas, legisladores e juristas têm a tarefa comum de ressignificar o paradigma de desenvolvimento nacional, considerando agora novas variáveis na sua equação geopolítica, tais como o fenômeno da desglobalização, a guerra comercial dos gigantes estadunidense e chinês, a consolidação de estruturas anti-hegemônicas de poder mundial etc. (Góes e Visentini 2019, 35).

I4 Ora que não se olvide que, desde o fim da mundialidade eurocêntrica, os EUA sempre controlaram a cena internacional pensando nos seus interesses vitais em primeiro lugar. Portanto, sem ingenuidade estratégica e sem zotismo acadêmico, é preciso compreender que todas as grandes estratégias anteriores à implantação do "América em primeiro lugar" sempre colocaram os EUA em primeiro lugar. Nesse sentido, o estudo sistemático até aqui realizado já demonstrou a dimensão hegemônica que orienta a atuação norte-americana no sistema internacional, ou seja, desde o fim da Segunda Guerra Mundial, o gênio pragmático do estrategista norte-americano vem fazendo uso de axiomas que articulam grandiosas alianças 
priorizar o espaço interno norte-americano antes reservado aos interesses difusos insculpidos nos grandes arranjos multilaterais supostamente controlados pelos Estados Unidos da América.

Na América de Trump, já não há mais espaço para a globalização neoliberal capitaneada por amplos arranjos multilaterais de comércio, que nada mais fazem do que prejudicar a economia dos EUA, em prol da China, potência antagônica e estrategicamente acoplada às redes da globalização ${ }^{\mathrm{I}}$. Eis aqui o grande paradoxo da ordem mundial pós-crise de 20I9: uma reviravolta no mundo americano, fruto de uma globalização neoliberal, que lhe escapa ou pelo menos se afasta gradualmente do seu controle direto e imediato. Com isso, impedir o domínio global chinês passa a ser o imperativo categórico da geopolítica estadunidense, daí a ideia de desglobalização a partir da Estratégia do America First ${ }^{\mathrm{t}}$.

Ou seja, o mundo pós-Covid-I9 será caracterizado pelo esforço dos Estados Unidos no sentido de evitar a ordem mundial multipolar, como se o seu poderio de antanho pudesse subsistir por si mesmo diante da nova realidade pós-crise mundial. Enfim, o mundo pós-coronavírus será um tempo marcado pela disputa entre o resgate da globalização neodarwinista de cunho neoliberal-lockeano e a consolidação da multipolaridade welfarista de viés cosmopolita-kantiano.

\section{A Geopolítica Brasileira do Século XXI à luz da Constituição Cidadã de 1988}

Como amplamente visto, a geopolítica pós-pandemia mundial

internacionais em benefício próprio (Góes 2018, 528).

I5 É nesse sentido que cabe questionar: quais seriam as razões geopolíticas que levam o gênio pragmático do estrategista norte-americano a desconstruir sua própria criação, talvez sua obraprima do tempo presente e que é a iniciativa das grandes alianças transoceânicas (atlântica e pacífica), concebidas pelo seu antecessor Barack Obama, exatamente como a finalidade conter o avanço chinês no mundo globalizado? De tudo se vê, por conseguinte, que a NSS de Trump é aparentemente contraditória com a posição de líder da ordem mundial neoliberal até então ocupada pelos Estados Unidos. Como entender, em pleno século XXI, a geopolítica norteamericana desconstruindo a globalização neodarwinista, que ela mesmo edificou diretamente desde a queda do muro de Berlim, em ig89? (Góes 2018).

I6 Com isso, inaugura-se a era do retrocesso da globalização, na qual a América de Trump, até então poderosa e mundialmente hegemônica, resolve enfrentar diretamente a China, classificando-a como rival, juntamente com a Rússia, como bem estabelece o próprio texto da sua estratégia de segurança nacional. Com efeito, a NSS de Trump desconstrói a globalização neodarwinista, que os Estados Unidos edificaram diretamente desde a queda do muro de Berlim, em I989. 
vivenciará a tensão entre o resgate da globalização neoliberal liderada pela China e o restabelecimento ou não da musculatura geopolítica dos Estados Unidos para retomar as rédeas de sua liderança global a partir de um cenário de desglobalização da economia. Infelizmente, no meio desse complexo contexto mundial, países de modernidade tardia do Sul Global, desorientados e sem saber para onde caminhar, tornam-se objeto de disputa desses gigantes geopolíticos. Com efeito, submetidos ao jogo de narrativas conflitantes de potências globais, notadamente EUA e China, é muito provável que sejam facilmente seduzidos pelo princípio geopolítico do alinhamento benigno (venha para o meu lado, que te ofereço maiores benefícios).

Aqui é importante entender que tal princípio traz ínsito o novo conceito de lebensraum (espaço vital) da estatalidade pós-moderna, qual seja a conquista de mercados e mentes. Tal cosmovisão permite interpretar, sem zotismo acadêmico, o que é verdadeiramente a globalização neoliberal, seus benefícios e malefícios, circunscritos a uma complexa dinâmica de domínio geopolítico do planeta, que se materializa pela liderança global, seja ela estadunidense ou chinesa ${ }^{\text {I7 }}$.

Em consequência, é preciso compreender que o fenômeno da globalização da economia não é mero instrumento de regulação do comércio internacional, nem tampouco instrumento de promoção de cooperação internacional benigno pela própria natureza, mas, sim, um instrumento de disputa de poder global (Góes 20I8). Nesta fase da globalização neoliberal pós-crise de 20I9, é imperioso marcar bem a imagem da Constituição de um Estado periférico recepcionando acriticamente conteúdos normativos que lhe são desfavoráveis e advindos da geopolítica hegemônica dos centros mundiais de poder, cuja força de influência chega mesmo a controlar o processo legislativo dos países de modernidade tardia do Sul Global.

Com a maestria reflexiva que lhe é peculiar, Norberto Bobbio mostra que o Poder Legislativo de países pobres da periferia do sistema internacional já não atua mais como poder autônomo, mas, sim, como mera câmara de ressonância de decisões estrangeiras, notadamente das nações líderes da globalização neoliberal da economia ${ }^{18}$.

I7 Nesse sentido, Parag Khanna destaca: Meio século depois, um exemplar com capa de couro da primeira edição da narrativa de Toynbee foi meu guia mais seguro quando comecei a percorrer o mundo para investigar a interação entre duas forças históricas mundiais que ele percebeu intuitivamente, sem chegar a lhes dar nome: a geopolítica e a globalização. A Geopolítica é a relação entre poder e espaço. Globalização remete à ampliação e ao aprofundamento das ligações entre os povos do mundo por meio de todas as formas de troca (Khanna 2008, 9-Io). ı8 O parlamento, na sociedade industrial avançada, não é mais o centro do poder real, mas apenas, frequentemente, uma câmara de ressonância de decisões tomadas em outro lugar (Bobbio 2004, I59). 
É por tudo isso que se tem a impressão de que o legislador pátrio não compreende bem a complexa matriz de impactos cruzados que circunscreve as relações verticalizadas de poder entre centro e periferia do sistema mundial. Nossas Constituições e leis são modificadas sem qualquer relação com um possível projeto nacional de desenvolvimento, ao revés, o que prepondera é a estratégia das grandes potências, notadamente Estados Unidos e China, caracterizando-se aquilo que podemos denominar de mercado de Constituições ${ }^{\mathrm{I}}$.

Quanto maior a falta de visão estratégica desse segmento da sociedade, maior será a intensidade dos danos sofridos pelos cidadãos comuns. Enfim, o resultado desta falta de compreensão da geopolítica mundial - de juízes e legisladores - reverbera diretamente no desenvolvimento nacional e, na sua esteira, na garantia de direitos sociais de hipossuficientes. Igualmente forte, é o registro de que as pessoas estão mais ricas do que os Estados nacionais. Tudo isso a refletir o fenômeno da globalização neodarwinista que nada mais faz senão perpetuar o ciclo da periferia do Sul Global. Nesse sentido, há que se lutar contra a realidade que vincula o "poder hegemônico de países ricos e industrializados" e as "modificações constitucionais subservientes de países pobres e subdesenvolvidos".

Nesse mesmo diapasão, o já citado Natalino Irti, jurista italiano de escol e professor da Università La Sapienza di Roma, demonstra que, por detrás de qualquer ordenamento jurídico, existe sempre uma vítima do poder, daí a concepção de uma era de desregulamentação e transações econômicas sem limites, na qual:

As transações econômicas ignoram os limites. Enquanto as tribos estão em guerra, entre outras coisas, na escuridão da noite, giram os mercados, que oferecem bens e os negociam, sentindo-se fora de qualquer pátria. Uma terra de ninguém é aquela que está entre as duas margens, entre as fronteiras de dois países, de dois espaços diferentes. A economia é (ou aspira ser) uma indefinida terra de ninguém (Irti 2007, I-4).

I9 A ideia de mercado de Constituições deriva diretamente da atuação das forças de (des) limitação de Natalino Irti (mercado de ordenamentos jurídicos) significando o poder que as empresas multinacionais - amparadas por seus respectivos Estados nacionais - têm para escolher aquela Constituição que lhes for mais vantajosa e conveniente dentro de um amplo mercado de Constituições, que lhes oferecem os países subdesenvolvidos do Sul Global (Irti $2007,6)$. E mais grave ainda é perceber que esta ideia-força de um mercado de Constituições, que a periferia do sistema internacional oferece para as empresas multinacionais, não surge do nada, mas, é, sim, fruto de uma decisão política fundamental do Estado tomada pelo seu Poder Legislativo, fazendo valer mais do que nunca aquela visão de Bobbio de mera câmara de ressonância de decisões tomadas em outro lugar. 
Tal tipo de intelecção não pode escapar ao estudioso do direito constitucional hodierno, na medida em que se reconhece que seu grande desafio científico no século XXI é o de incorporar, na equação constitucional, novas variáveis metajurídicas (geopolíticas, econômicas, culturais etc.), que informam e conformam a elaboração da ordem jurídica como um todo $^{2 \circ}$. Com efeito, em tempos de estatalidade pós-moderna, geopolítica, globalização e direito mesclam-se de tal maneira que passam a formar um todo epistemológico, que desafia juristas e estrategistas do século XXI, daí a relevância do geodireito enquanto ramo multidisciplinar da ciência contemporânea.

Em termos rigorosamente jurídicos, a Constituição Cidadã de I988 estabelece como núcleo fundante do Estado Democrático Direito, a consecução dos objetivos fundamentais insculpidos no artigo terceiro do texto constitucional $^{21}$. No entanto, observe, com atenção, que, dentre tais objetivos fundamentais do Estado brasileiro, encontra-se a garantia do desenvolvimento nacional, cuja consecução depende diretamente da geopolítica nacional. Isto significa dizer que o desenvolvimento nacional não é mera questão estratégica deixada a cargo do estrategista pátrio, mas, sim, norma de dignidade constitucional, que deve ser ponderada em face dos demais princípios da Constituição.

Nesse sentido, não basta reaproximar o direito e a ética, como o faz brilhantemente o paradigma neoconstitucionalista do direito; é preciso transpor limites dogmáticos para alcançar a plena sintonia entre geopolítica e direito, de modo a criar as bases teóricas da hermenêutica do desenvolvimento nacional, na qual a questão estratégica será levada em consideração no

20 Contemporaneamente, o Poder Judiciário - na qualidade de componente das forças políticas do Estado - se vê cada vez mais envolvido nos complexos problemas constitucionais que são levados para os tribunais, valendo destacar, desde logo, as questões de ordem geopolítica, tais como, a demarcação das terras indígenas, as questões do meio ambiente versus construção de hidrelétricas na Amazônia, o plano de desinvestimento da Petrobras e seu processo de desverticalização pela privatização de subsidiárias (Refinarias, BR Distribuidora e outras), a privatização do Sistema Eletrobras, o marco regulatório do pré-sal: regime de partilha ou regime de concessões? e muitas outras questões geopoliticamente quejandas. São questões que tais que perfazem o assim chamado constitucionalismo estratégico, vale definir, o ramo do direito constitucional, cuja linhagem epistêmica se concentra no estudo inter, trans e multidisciplinar envolvendo a geopolítica mundial e o direito constitucional interno (Góes 20I9).

2I Os objetivos fundamentais do Brasil são, nos termos do art. $3 \mathrm{ffl}$, incisos I a IV, da CRFB/88, construir uma sociedade livre, justa e solidária; garantir o desenvolvimento nacional; erradicar a pobreza e a marginalização e reduzir as desigualdades sociais e regionais e promover o bem de todos, sem preconceitos de origem, raça, sexo, cor, idade e quaisquer outras formas de discriminação. 
processo de ponderação de valores constitucionais em colisão. Um país sem estratégia de desenvolvimento nacional é um país à deriva que, sem rumo, não sabe aonde quer chegar.

Portanto, como já dito, a incompreensão do jogo estratégico mundial por parte de legisladores, juízes e tribunais pode representar a mitigação de direitos sociais das classes menos favorecidas, em virtude de uma possível desindustrialização do País. É nesse sentido que urge questionar se é possível construir uma sociedade livre, justa e solidária sem uma estratégia de industrialização do País genuinamente nacional e focada na distribuição de renda? Da mesma forma, impende perguntar se é possível garantir o desenvolvimento nacional sem a concepção de um grande projeto estratégico de Estado; e mais: como erradicar a pobreza e a marginalização, bem como as desigualdades regionais e sociais, adotando-se uma estratégia de subordinação aos interesses vitais dos centros mundiais de poder?

Enfim, a falta de uma visão clara dessa ordem de considerações pode dificultar a elaboração de um projeto geopolítico genuinamente brasileiro, livre de interferências externas. É nesse diapasão que urge construir um arquétipo geopolítico autóctone, com aptidão de gerar o desenvolvimento nacional, sem violar os princípios do Estado Democrático de Direito, garantindo assim vida digna para todos os brasileiros ${ }^{22}$. Para tanto, defende-se aqui a tese de que a projeção internacional do Brasil perpassa, inexoravelmente, pelo avanço do saber geopolítico nacional, muitas vezes distorcido ou mal compreendido, seja no Congresso Nacional, seja no Poder Judiciário, o que dificulta a consecução do imperativo categórico da geopolítica brasileira: conduzir o Brasil ao seu devido lugar no sistema internacional, qual seja, estar entre as cinco maiores potências mundiais do planeta.

Destarte, no Brasil, não se pode negar a lacuna relativa ao encontro epistemológico da geopolítica e do direito, valendo destacar aqui a visão de Gilberto Bercovici, quando captura com precisão a falta de preocupação com o desenvolvimento:

22 E assim é que geopolítica e poder devem estar em consonância com o sentimento constitucional de desenvolvimento social e econômico, não se admitindo mais aquela vetusta imagem autopoiética positivista, fechada em si própria, sem acoplamento conceitual dos diferentes fluxos epistemológicos, notadamente da geopolítica e do direito. Ao contrário, é tarefa do jurista/estrategista brasileiro superar o atraso científico que nos separa dos países desenvolvidos, em especial dos Estados Unidos da América, cuja Grande Estratégia (National Security Strategy) tem o poder de moldar a ordem internacional; repita-se por fundamental: a estratégia de um único país direcionando e comandando o contexto mundial (Góes e Visentini 20I9, 3I). 
Podemos jogar o que quisermos na Constituição, se não tivermos um Estado forte, no sentido republicano, para implementar essa Constituição, para poder garantir os direitos, para poder implementar políticas públicas, de nada adianta. (...) Outra questão que ignoramos ultimamente é a questão do desenvolvimento. Sem um Estado que promova uma efetiva política de desenvolvimento, podemos colocar o que quisermos na Constituição, e, infelizmente, estaremos condenados a ficar denunciando o fato de a que Constituição prevê algo que na realidade não se concretiza (Bercovici 2003, 79) (grifos dos autores).

Assim, o grande desafio do pensamento acadêmico nacional do tempo presente é conceber um arquétipo epistemológico multidisciplinar que harmonize as relações entre a "Grande Estratégia Nacional" e a "Constituição Cidadã de I988"23. Como bem destaca Lassalle (I998, 49), os problemas constitucionais não são problemas de direito, mas do poder. Ou seja, a decisão judicial não pode prescindir da compreensão da geopolítica mundial e seus reflexos no campo constitucional e vice-versa, exatamente como preleciona Philip Bobbitt (2003, I92), a constituição não é apenas o documento que manifesta as maneiras pelas quais determinada sociedade reconhece direitos civis, pelo contrário, as sociedades, todas elas, são constituídas de determinada forma, e essa forma é a sua constituição.

Em tempos de estatalidade pós-moderna, intensifica-se a conexão científica entre a hermenêutica de desenvolvimento nacional e a plena efetividade de direitos fundamentais do homem brasílico a partir da judicialização da geopolítica. Para o bem ou para o mal, o STF necessita conhecer os impactos da geopolítica mundial não apenas sobre nossa Carta Ápice, mas, também, sobre o ordenamento jurídico como um todo. Urge, pois, fixar as bases de um corpus epistêmico-geopolítico autóctone, com grau de ordem e racionalidade que permita a maximização do desenvolvimento nacional sem violação dos cânones do Estado de Direito. Para tanto é necessário planejar e agir, o que evidentemente ressalta a força de uma geopolítica independente (Góes e Visentini 2019, 30).

Esta é a razão pela qual o estadista/legislador pátrio tem que repensar

\footnotetext{
23 Por um lado, como já visto, o conceito de Constituição em sentido estratégico pressupõe o mapeamento teórico em torno do fenômeno da judicialização da geopolítica, no qual as grandes questões estratégicas do Estado brasileiro serão levadas para a apreciação do Poder Judiciário. Assim, a ideia de Constituição Estratégica projeta a imagem de "ato de constituir a ação estratégica do Estado", o que evidentemente significa dizer que a Constituição deve ser lida com filtro estratégico, capaz de compreender a influência dos fatores reais de poder não apenas no campo interno, tal qual a célebre tese de Ferdinand Lassalle, de I862, mas, principalmente, dos fatores reais de poder hegemônico no plano da geopolítica mundial (Lassalle I988).
} 
um novo paradigma de estatalidade positiva atenuada, que harmonize de um lado o binômio "livre iniciativa - expansão mundial do comércio" e, do outro, o trinômio "dignidade da pessoa humana - desenvolvimento nacional - justiça social". E mais: a confluência dos valores liberais (igualdade formal e estatalidade mínima) com os valores sociais (igualdade material e estatalidade positiva) deve ser feita a partir da garantia do núcleo essencial da dignidade humana, que fixa as condições materiais mínimas para o exercício pleno da cidadania e dos direitos de todas as três dimensões para todos os indivíduos.

Com a devida acuidade científica, o leitor haverá de concordar que a garantia do núcleo essencial da dignidade da pessoa para todos os cidadãos somente será alcançada com o fortalecimento e expansão do núcleo estratégico brasileiro. Como já dito, entenda-se como núcleo estratégico brasileiro o conjunto de empresas brasileiras que se aproximam das empresas multinacionais tradicionais do capitalismo democrático, na medida em que permanecem como polos de produção mundial e não como meros mercados consumidores (importação direta de produtos vindos do exterior). Nessa categoria de empresas, dentre outras, Petrobras, Embraer, Base Industrial de Defesa, AmBev, Braskem, Banco do Brasil, Indústria Naval e Aeronáutica, Vale do Rio Doce, Eletrobras, Empreiteiras Nacionais e Agronegócio.

Observe, com atenção, que somente com esse espectro conceitual do geodireito (expansão do núcleo estratégico de empresas brasileiras garantindo o núcleo essencial de vida digna para os cidadãos brasileiros), é possível projetar o futuro geopolítico do País. Expandir o núcleo estratégico brasileiro não significa reduzir o número de empresas estatais e multinacionais de outras nacionalidades. Ao contrário, em vários setores estratégicos da economia nacional, urge atrair novos investimentos estrangeiros com o fito de fomentar o desenvolvimento nacional ${ }^{24}$.

Aqui, o leitor deve compreender, com a devida sensibilidade estratégica, que não se trata de ser contra as privatizações, ao contrário, defende-se aqui a tese de que as privatizações sempre serão bem-vindas, na medida em que empresas estatais serão sempre menos competitivas do que as empresas privadas. Na verdade, o que não pode ocorrer é a desnacionalização, seguida de completa liquidação de empresas brasileiras (estatais ou privadas), algumas

24 O que não se admite é a redução do núcleo estratégico brasileiro, feito por privatizações, que transferem a atividade industrial para o exterior, com importação superveniente daquele mesmo produto no futuro. Lógica não muito fácil de compreender, mas, induvidosamente, lógica imposta quase que por intermédio de pensamento único, no primeiro ciclo de privatizações do Estado brasileiro, na década de noventa. Um bom modelo de privatização de empresas públicas é o processo de abertura de capital na bolsa de valores, com pulverização de ações, o que permitiria o controle estratégico de tais empresas pela sociedade brasileira e não pelo Estado brasileiro, bem como a manutenção de polos de desenvolvimento tecnológico no Brasil. 
rentáveis e dotadas de razoável domínio tecnológico, como, foi, por exemplo, a indústria naval brasileira, até então situada entre as três primeiras do mundo e cujo desfecho foi melancólico: um setor estratégico da economia nacional foi praticamente dizimado em nome de uma competitividade internacional que nunca chegou ao País.

Enfim, da noite para o dia, operou-se a quase destruição desse relevante núcleo estratégico brasileiro, de alto valor agregado e considerável teor tecnológico, restando ao País despender bilhões de dólares em pagamento de frete para navios de bandeira estrangeira realizarem o comércio marítimo, que corresponde a mais de $90 \%$ de todo o comércio exterior do Brasil. Fica aqui o registro de um exemplo fundamental, que reforça a necessidade do desenvolvimento do geodireito, enquanto ramo da ciência jurídica que estuda as conexões epistemológicas imanentes entre a geopolítica e o direito ${ }^{25}$.

De tudo se vê, portanto, que um dos grandes desafios do jurista/ estrategista brasileiro do século XXI é fazer a revisão teórica de instrumentos geopolíticos e jurídicos, que projetem a formulação de políticas públicas de revalorização da indústria nacional, sem violar os ditames do Estado Democrático de Direito e sem violar as regras internacionais do livre comércio. Com rigor, são as empresas multinacionais que moldam a ordem mundial sob a proteção dos seus respectivos Estados nacionais.

É urgente, pois, construir um novo paradigma estatal, com latitude científica capaz de harmonizar a tensão do jogo geopolítico de poder do sistema internacional e o sentimento constitucional de justiça, viabilizando dessarte o fortalecimento do núcleo estratégico de industrialização do País e, na sua esteira, garantindo o núcleo essencial de vida digna para o homem brasílico em geral. Urge, portanto, articular os elementos do Poder Nacional, transformando poder potencial em poder real e projetando o País no concerto das nações, notadamente a partir dos seus quatro grandes arquétipos geopolíticos fundantes, que posicionam o Brasil como uma superpotência energética, uma superpotência alimentar, uma superpotência aquífera e uma superpotência ambiental (superpotência verde).

E mais: o estudo da geopolítica clássica e contemporânea mostra claramente a linha periférica que caracteriza a América do Sul em relação aos centros de poder, o que naturalmente não se coaduna com a dimensão político-estratégica do Brasil. Com efeito, admitir relações geopolíticas verticalizadas é fator impeditivo para o Brasil prosperar em ritmo próprio, concretizando assim o grande imperativo categórico da geopolítica brasileira. É por isso que, em sentido acadêmico, ganha relevância a teorização feita pelo Coronel Roberto Machado de Oliveira Mafra da Escola Superior de Guerra ao engendrar a sua Teoria do Quaterno. Seu grande mérito repousa na 
ideia-força de que o Brasil e os demais países latino-americanos não devem aceitar tratamento inferiorizado por parte dos demais blocos ou lideranças mundiais ${ }^{26}$.

Muito embora a concepção do quaterno do eminente professor da ESG seja a melhor trajetória a seguir, notadamente, nos termos do parágrafo único, do artigo quarto, da Constituição de I988, que estabelece a busca pela formação de uma comunidade latino-americana de nações, acredita-se que tal constructo geopolítico seja de difícil execução a médio ou curto prazos ${ }^{27}$. Assim, conjectura-se como melhor solução geopolítica a redução do espaço vital do Brasil para o subcontinente sul-americano. Isto não significa dizer que a integração sul-americana seja o cerne da geopolítica brasileira do século XXI. Ao contrário, a busca pela integração sul-americana é apenas o ponto de partida de um projeto geopolítico muito mais amplo e que se projeta sobre as estruturas do macropoder mundial, notadamente os Estados Unidos, a União Europeia e a China.

Eis aqui o núcleo fundante da geopolítica brasileira do século XXI: a construção de um arquétipo de fortalecimento da América do Sul face aos três grandes polos de atração do poder mundial, daí a importância da reaproximação estratégica com os Estados Unidos, o avanço do acordo Mercosul-União Europeia e o acoplamento à iniciativa chinesa do Cinturão Econômico e da Rota da Seda Marítima.

\section{Considerações Finais}

O presente trabalho procurou analisar, inicialmente, o controle geopolítico do direito a partir da influência da geopolítica neoliberal sobre o constitucionalismo dos países de modernidade tardia, como, amplamente visto, é o caso do Brasil. Assim, foi possível demonstrar a influência dos fatores reais de poder mundial sobre o processo legislativo dos países do Sul Global a partir da globalização neoliberal, cuja liderança está sendo disputada pelos Estados Unidos e China.

Pela sistematização engendrada, foi possível constatar que a NSS de Trump, antes mesmo da crise do coronavírus de 20I9, já apresentava estrutura cratológica incompatível com a posição de líder da globalização neoliberal, até então ocupada pelos Estados Unidos. Como entender, em pleno século XXI, a geopolítica norte-americana desconstruindo a globalização neodarwinista, que ela mesma edificou diretamente desde a queda do muro de Berlim, em I989? (Góes 2018, 529).

Nesse sentido, demonstrou-se que a Estratégia de Trump não 
era apenas a versão mais atualizada da doutrina isolacionista da era eurocêntrica, mas, principalmente, um marco de ruptura paradigmática com todos os outros arquétipos estratégicos que lhe antecederam. Ou seja, a América de Trump, denegando a teoria da tríade, afastou-se da liderança do globalismo neoliberal, para se aproximar da racionalidade neoisolacionista, verdadeiramente protecionista, que viabilizou o tão propalado "giro geopolítico da desglobalização", provocado, por sua vez, pelo engrandecimento do poder chinês, que se consolidou com a convergência entre o Cinturão Econômico da Rota da Seda (por terra) e a Rota da Seda Marítima do Século XXI (por mar).

Assim, evidenciou-se que a crise da Covid-ıg reforçou ainda mais essa visão de sucesso chinês sobre os EUA no que tange à sua capacidade de influência internacional e de controle da economia globalizada. A emergência sanitária comprovou a dependência mundial dos equipamentos de saúde fabricados na China, daí a tentativa estadunidense de neutralização geopolítica da expansão chinesa, não apenas em relação à conquista da ilha mundial mackinderiana (massas terrestres da Europa, Ásia e África), mas, também, do crescente exterior ou insular (as terras do continente americano, da Austrália e adjacências) ${ }^{28}$.

Enfim, asseverou-se que o mundo pós-coronavírus a ser refeito vivenciará a tensão geopolítica entre o resgate da globalização neoliberal liderada pela China e a retomada de musculatura cratológica dos EUA para reassumir as rédeas da liderança global. No meio disso tudo, a legítima aspiração dos países de modernidade tardia pela busca do seu desenvolvimento nacional.

Foi nesse diapasão, que se destacou que o estadista/legislador pátrio tem que repensar um novo paradigma estatal, considerando agora novas formas de relações internacionais e novas fórmulas de interpretação da Constituição. A solução vislumbrada terá que privilegiar a expansão do núcleo estratégico brasileiro, enquanto conjunto de segmentos econômico-tecnológicos autônomos capazes de participar eficazmente da competição internacional. Ou seja, um país com mais de 200 milhões de habitantes não pode abrir mão do seu núcleo estratégico tecnológico-industrial, transformando-se em mera sociedade de serviços, exportadora de produtos primários.

Comefeito, dentro deum cenárioqueé, aum sótempo, geopoliticamente pós-americano, estadisticamente pós-welfarista e juridicamente póspositivista, urge ao juiz/jurista do século XXI conceber um novo arquétipo constitucional de estatalidade positiva atenuada, que harmonize de um lado o binômio "livre iniciativa - expansão mundial do comércio" e, do outro, o trinômio "dignidade da pessoa humana - desenvolvimento nacional - 
sentimento constitucional de justiça" ${ }^{29}$.

Há que se compreender que a Constituição e a Estratégia Nacional enquanto definidora de políticas públicas - são faces de uma mesma moeda, que se encontram na consecução dos objetivos fundamentais do Estado brasileiro. De que adianta comemorar-se a força normativa da Constituição sob a égide de uma pujante democracia, quando se constata a inaptidão do País para conceber uma estratégia de desenvolvimento nacional genuinamente brasileira que garanta, ao mesmo tempo, o núcleo estratégico das empresas brasileiras e o núcleo essencial de dignidade humana de todos brasileiros?

Na virada do século XX para o século XXI, a consecução do grande imperativo categórico da geopolítica brasileira será o grande avisador de tempos felizes no encontro da garantia do núcleo essencial de vida digna para todos os brasileiros com a expansão do núcleo estratégico das grandes empresas multinacionais brasileiras. Esta é a única maneira de vencer o ciclo da periferia, colocando o Brasil entre as cinco primeiras potênciais mundiais.

\section{REFERÊNCIAS}

Agamben, Giorgio. 2020. "Reflexões sobre a peste". In: Ensaios em tempos de pandemia. Tradução de Isabella Marcatti. São Paulo: Boitempo.

Barretto, Vicente de Paulo. 20ıo. O fetiche dos direitos humanos e outros temas. Rio de Janeiro: Lumen Juris.

Barroso, Luís Roberto. 2003. "Fundamentos Teóricos e Filosóficos do Novo Direito Constitucional Brasileiro (Pós-modernidade, teoria crítica e pós-positivismo)". In: Barroso, Luís Roberto (Org.). A nova interpretação constitucional. Ponderação, Direitos fundamentais e Relações Privadas. São Paulo-Rio de Janeiro: Renovar.

Bauman, Zygmunt. 2008. Medo líquido. Tradução de Carlos Alberto Medeiros. Rio de Janeiro: Jorge Zahar.

Bercovici, Gilberto. 2003. In: Coutinho, Jacinto Nelson de Miranda (Org.). Canotilho e a constituição dirigente. Organizador. Rio de Janeiro: Renovar.

Bobbitt, Philip. 2003. "A guerra e a paz na história moderna”. In: O impacto dos grandes conflitos e da política na formação das nações. Tradução de Cristiana de Assis Serra. Rio de Janeiro: Campus.

Bobbio, Norberto. 2004. A era dos direitos. Tradução de Carlos Nelson Coutinho. Rio de Janeiro: Elsevier.

Brzezinski, Zbigniew. 2007. Second chance: three presidents and the crisis of american superpower. New York: Basic Books. 
Friedman, Thomas. 2007. O mundo é plano: uma breve história do século XXI. Rio de janeiro: Objetiva.

Fukuyama, Francis. 1998. O fim da história. Rio de Janeiro: Biblioteca do Exército.

Góes, Guilherme Sandoval; Visentini, Paulo Fagundes. 20I9. "Escola Superior de Guerra: 70 anos pensando segurança, desenvolvimento e geopolítica”. REVISTA DA ESCOLA SUPERIOR DE GUERRA 34: 13-38.

Góes, Guilherme Sandoval. 2or8. “Geopolítica Mundial e America’s Grand National Strategy: diálogos epistemológicos indissociáveis". REVISTA DA ESCOLA DE GUERRA NAVAL (ED. PORTUGUÊS) 24: 500542.

Góes, Guilherme Sandoval, Massera, Hector Villagra. 2015. Brasil e Chile: posição geopolítica no contexto mundial contemporâneo. Rio de Janeiro: Editora da ESG.

Góes, Guilherme Sandoval. 20I9. "Estado Estratégico de Direito e judicialização da geopolítica: Desafios do direito constitucional contemporâneo". In: Mello, Cleyson at al. (Org.). Estudos em Homenagem ao Professor Doutor José Rogério Moura de Almeida Filho: Saúde, Direito, Educação, Inovação e Cidadania. Rio de Janeiro-RJ: Processo (I): 68I7IO.

Huntington, Samuel. I998. O choque de civilizações e a recomposição da ordem mundial. Rio de Janeiro: Biblioteca do Exército.

Irti, Natalino. 2005. Norma e luoghi. Problemi di geo-diritto. Roma-Bari: Laterza.

Irti, Natalino. Geodireito. 2007. Tradução de Alfredo Copetti Neto e André Karan Trindade. Conferência sobre biodireito e geodireito. Universidade de São Paulo, São Paulo.

Jameson, Fredric. 2002. Pós-Modernismo: A lógica cultural do capitalismo tardio. São Paulo: Ática.

Khanna, Parag. 2008. O segundo mundo. Impérios e influência na nova ordem global. São Paulo: Intrínseca.

Lassalle, Ferdinand. I998. A essência da constituição. 2ed. Rio de Janeiro: Liber Juris.

Lipovetsky, Gilles. 2004. Os tempos hipermodernos. São Paulo: Barcarolla.

Lyotard, Jean-François. 2004. A condição pós-moderna. Tradução de Ricardo Corrêa Barbosa. 8 ed. Rio de Janeiro: José Olympio.

Mafra, Roberto Machado de Oliveira. 2006. Geopolítica: introdução ao estudo. São Paulo: Sicureza.

Moniz Bandeira, Luiz Alberto. 20I6. A desordem mundial: O espectro da total 
dominação: Guerras por procuração, terror, caos e catástrofes humanitárias. Rio de Janeiro: Civilização brasileira.

United States. I996. U. S. National Strategy of Engagement and Enlargement. Administration of William Clinton. Washington, D.C. Press, febl. I996.

United States. 2002. U.S. National Strategy of Defending The Nation Agaisnt Its Enemies. Administration of Georg W. Bush. Washington, D.C. Press, sep. 2002.

United States. 20I0. U.S. National Strategy of Nation Renewal and Global Leadership. Administration of Barack Obama. Washington, D.C. Press, may. 2010.

United States. 20I7. U.S. National Strategy of Making America Great Again. Administration of Donald Trump. Washington, D.C. Press, dec. 20I7.

\section{RESUMO}

O presente artigo é fruto de pesquisa desenvolvida no estágio pós-doutoral do Programa de Pós-Graduação em Ciências Aeronáuticas da Universidade da Força Aérea (PPGCA), cujo tema era "Geopolítica, Cultura e Direito: Diálogos epistemológicos necessários em tempos de estatalidade pós-moderna". Assim sendo, colima examinar as conexões científicas que unem a geopolítica e o direito, disciplinas que se imbricam de tal maneira que acabam desaguando na garantia de direitos fundamentais para o cidadão comum. Busca-se analisar o controle geopolítico do direito a partir da influência da geopolítica neoliberal sobre o constitucionalismo dos países de modernidade tardia, como é o caso do Brasil. Assim, foi possível demonstrar a influência dos fatores reais de poder mundial sobre o processo legislativo dos países do Sul Global a partir da globalização neoliberal, cuja liderança está sendo disputada pelos Estados Unidos e China.

\section{PALAVRAS-CHAVE}

Geopolítica; Relações Internacionais; Estado; Direito.

Recebido em 4 de novembro de 2020 Aprovado em 16 de novembro de 2020 